\title{
Comportamento ingestivo de novilhos mestiços em pastagens tropicais manejadas em diferentes alturas ${ }^{1}$
}

\section{Fabíola Cristine de Almeida Rego ${ }^{2}$, Júlio César Damasceno ${ }^{3}$, Nelson Massaru Fukumoto 4 , Cristiano Côrtes ${ }^{4}$, Lauri Hoeshi ${ }^{4}$, Elias Nunes Martins ${ }^{3}$, Ulysses Cecato ${ }^{3}$}

\author{
${ }^{1}$ Parte da tese de Doutorado apresentada pela primeira autora à Universidade Estadual de Maringá - UEM \\ 2 Universidade Norte do Paraná - UNOPAR. \\ 3 Universidade Estadual de Maringá - UEM. Pesquisador do CNPq. \\ ${ }^{4}$ Pós-graduação em Zootecnia - UEM
}

RESUMO - Foi avaliado o comportamento ingestivo de novilhos mestiços em pastagens exclusivas de capim-marandu (Brachiaria brizantha Stapf Hoesch cv. Marandu), capim-tanzânia (Panicum maximum Jacq. cv. Tanzânia) e amendoim forrageiro (Arachis pintoi cv. Amarillo) e em pastagem consorciada de capim-marandu e amendoim forrageiro, em resposta à altura do relvado. As parcelas foram reguladas em seis alturas nas pastagens de gramíneas e, naquelas de amendoim forrageiro e consorciada, foram rebaixadas simulando o pastejo intermitente. A quantidade de forragem ingerida pelo animal foi determinada pela técnica de dupla pesagem. A taxa de ingestão (TI, g MS/minuto) foi estudada em função da altura da pastagem (A) e da massa de folhas (MFV), denominadas variável $Z$ no modelo: TI $=\operatorname{TImax}\left(1^{-} \mathrm{e}^{(-K} \mathrm{x} Z\right)$ ) em que: TImax é o parâmetro que representa a taxa de ingestão potencial máxima ( $\mathrm{g} \mathrm{MS} / \mathrm{min}) ; k$ é o parâmetro que representa a variação em TI para cada unidade de variação em $Z$. A TI variou conforme a altura da pastagem para todas as espécies, mas, para a MFV, variou apenas nas pastagens de amendoim forrageiro e capim-marandu. A TI potencial em função da altura da pastagem foi de $66,49 \mathrm{~g}$ MS/minuto, independentemente da pastagem avaliada, e foi mais sensível à variação na altura para o amendoim forrageiro, em comparação às demais pastagens $(\mathrm{k}=0,09$ vs 0,039$)$. A fração tempo despendido/g MS ingerido/bocado foi maior para o capim-tanzânia e a pastagem consorciada, com valores de 3,16 e 2,83 segundos, respectivamente. Para manipulação do capim-marandu e do amendoim forrageiro, o tempo despendido foi 0,80 e 0,68 segundo, respectivamente. A estratégia do animal para manter a TI elevada na pastagem de amendoim forrageiro foi aumentar a taxa de bocados e, nas demais pastagens, aumentar a ingestão por bocado.

Palavras-chave: altura da pastagem, ingestão por bocado, massa de folhas verdes, taxa de bocado, tempo por bocado

\section{Chewing behavior of crossbred beef steers on tropical pasture managed at different heights}

\footnotetext{
ABSTRACT - The chewing behavior of crossbred beef steers grazing pure swards of marandugrass (Brachiaria brizantha Stapf Hoesch cv. Marandu), tanzaniagrass (Panicum maximum Jacq. cv. Tanzânia), and forage peanut (Arachis pintoi cv. Amarillo) as well as a mixed sward of marandugrass plus forage peanut all managed to yield different heights was evaluated in this trial. Paddocks of grasses were managed through grazing to obtain six different heights while those of forage peanut and mixed pasture were lowered by using the intermittent grazing simulation technique. The amount of ingested forage was estimated using the double weighting method. The ingestion rate (IR, g DM/min) was determined according to pasture height $(\mathrm{PH})$ and green leaf mass $(\mathrm{GLM})$, both of which called as the $\mathrm{Z}$ variable in the model: $\mathrm{IR}=\operatorname{IRmax}\left(1-\left(1^{-} \mathrm{e}^{(-K} \times \mathrm{Z}\right)\right.$, where IRmax is the parameter that represents the maximum potential ingestion rate $(\mathrm{g} \mathrm{DM} / \mathrm{min})$ and $k$ is the parameter that represents the variation in IR per each unit of variation in Z. The IR changed in response to PH for all forages; however, the IR varied in response to GLM only for forage peanut and marandugrass. The IR, as function of PH, averaged $66.49 \mathrm{~g} \mathrm{DM} / \mathrm{min}$ across forages and was more sensitive to variation in $\mathrm{PH}$ for forage peanut than for the remaining species $(\mathrm{k}=0.09 \mathrm{vs} . \mathrm{k}=0.039)$. The time spent chewing each g DM per bite was greatest for the tanzaniagrass and the mixed sward averaging 3.16 and 2.83 seconds, respectively. Manipulation of marandugrass and forage peanut required 0.8 and 0.68 second, respectively. In order to keep high IR, animals on forage peanut increased the bite rate while those grazing the other forage species enhanced the amount of ingested feed per bite.
}

Key Words: biting rate, chewing time, intake per bite, green leaves mass, sward height 


\section{Introdução}

A estrutura espacial do relvado tem grande influência no comportamento de pastejo dos animais, com claros efeitos da altura das pastagens (Flores et al., 1993) e da disponibilidade dos itens preferidos pelos animais (Prache et al., 1998) sobre a taxa de ingestão instantânea e o peso e a taxa de bocado.

A facilidade com que o animal colhe as plantas depende das características estruturais do relvado, expressas principalmente pela massa de forragem (toneladas de MS por área), altura, relação caule:folha e pela densidade da biomassa total e de folhas (Combellas \& Hodgson, 1979).

Técnicas baseadas nas mudanças no peso do animal antes e após um ciclo curto de pastejo (Penning \& Hooper, 1985) têm sido utilizadas para estimativa da taxa de ingestão instantânea do animal. A taxa de ingestão é dependente da ingestão por bocado ( $\mathrm{g}$ MS) e da taxa de bocados (número de bocados por minuto), definidas em escalas temporais de curto prazo (minutos ou segundos) e limitadas por propriedades morfológicas da vegetação e pelo aparato ingestivo do animal (Ungar, 1996), o que confirma a importância da estrutura do relvado e seus impactos no comportamento ingestivo animal. A taxa de ingestão, entretanto, é um dos componentes do consumo diário (Hodgson, 1981).

A taxa de ingestão aumenta com a altura da pastagem ou massa de forragem até atingir uma assíntota, resultante da saturação da capacidade do animal em processar o alimento ingerido (Gordon \& Illius, 1996). Segundo Hodgson (1990), a resposta do consumo animal depende mais da altura da pastagem que da massa de forragem, principalmente em razão do efeito sobre a profundidade do bocado. Entretanto, a maioria dos trabalhos existentes foi realizada com espécies temperadas. Em revisão, Carvalho (2001) constatou que a profundidade do bocado é a variável que mais responde às variações na altura do dossel forrageiro, o que indica ser a variável determinante do volume do bocado.

Objetivou-se com esta pesquisa estimar a taxa de ingestão dos animais em diferentes pastagens tropicais, visando obter uma resposta funcional sobre o consumo de forragem em curto prazo, a altura da pastagem e a massa de folhas. As hipóteses consideradas foram: a taxa de ingestão é determinada pelas mudanças na estrutura da pastagem, que provocam alterações nas características do bocado; a altura da pastagem afeta as variáveis do comportamento ingestivo de novilhos.

\section{Material e Métodos}

O experimento foi conduzido no período de outubro de 2002 a fevereiro de 2003 na Fazenda Experimental da Universidade Estadual de Maringá, localizada no distrito de Iguatemi, região noroeste do Paraná. O solo é classificado como latossolo vermelho escuro (distrófico) (Embrapa, 1999) e o clima como subtropical úmido, mesotérmico (Cfa) (Corrêa, 1996), latitude 2322' '12' sul e longitude $52^{\circ} 03^{\prime}$ ' 54 ' oeste.

Foram avaliadas pastagens exclusivas de Brachiaria brizantha Stapf. cv Marandu (capim-marandu), Panicum maximum Jacq. cv. Tanzânia (capim-tanzânia), Arachis pintoi $\mathrm{cv}$. Amarillo (amendoim forrageiro) e outra consorciada de capim-marandu com amendoim forrageiro. O plantio da leguminosa foi realizado em maio de 2001 e o das gramíneas, em novembro do mesmo ano. As espécies foram adubadas no plantio com $800 \mathrm{~kg} / \mathrm{ha}$ da fórmula 0-10-10 (NPK). A aplicação de nitrogênio nas gramíneas puras foi feita a lanço, sob a forma de uréia, parcelada em três vezes $(70,70$ e $60 \mathrm{~kg} \mathrm{~N} / \mathrm{ha}$ ).

O capim-tanzânia foi estabelecido em seis parcelas de $44 \times 10 \mathrm{~m}$ e o marandu, em seis parcelas de $23,5 \times 9,5 \mathrm{~m}$. O amendoim forrageiro foi implantado em uma área de $1.800 \mathrm{~m}^{2}$, sem divisões. A pastagem consorciada ocupou uma área $3.840 \mathrm{~m}^{2}$, dividida em quatro parcelas de $12 \times 80 \mathrm{~m}$.

As parcelas de capim-marandu e de capim-tanzânia foram reguladas em diferentes alturas (Tabela 1) utilizando-se animais em pastejo (vacas e novilhas como animais reguladores) dois meses antes das avaliações, no intuito de se obter alturas (estruturas) contrastantes nas seis parcelas de cada espécie. Para isso, foi simulado o sistema de lotação contínua e carga variável.

No caso do amendoim forrageiro e da pastagem consorciada (Tabela 2), em virtude da dificuldade de se obter diferentes alturas, optou-se pela utilização da técnica grazing down, que consiste no rebaixamento da pastagem pelo efeito do pastejo animal, simulando-se o sistema de pastejo intermitente.

Para aferir a altura média por dia, foram considerados 130 pontos por piquete para as gramíneas exclusivas, 390 pontos por dia para a leguminosa e 245 para a pastagem consorciada. As médias de alturas das pastagens e as características morfológicas são descritas nas Tabelas 1 e 2 .

Os teores de FDN das folhas foram 38, 60, $51 \%$ e os das hastes $42,61,6$ e $61,9 \%$ para as pastagens de amendoim forrageiro, capim-tanzânia e capim-marandu, respectivamente. Na pastagem consorciada, os valores de FDN de folhas e hastes foram 55,9 e $64,9 \%$ para o capim-marandu e 40,7 e 50,1 para o amendoim forrageiro. 
Tabela 1 - Características morfológicas (médias e desvios-padrão) das pastagens de capim-marandu e capim-tanzânia durante o período experimental

Table 1 - Morphological characteristics (means and standard deviations) of marandugrass and tanzanaiagrass pastures during the experimental period

\begin{tabular}{|c|c|c|c|c|}
\hline $\begin{array}{l}\text { Altura } \\
\text { Height }\end{array}$ & $\begin{array}{c}\mathrm{MF}^{1} \\
F M\end{array}$ & $\begin{array}{c}\mathrm{MLV}^{2} \\
G L M\end{array}$ & $\begin{array}{c}\mathrm{MHV}^{3} \\
G S M\end{array}$ & $\begin{array}{c}\mathrm{MMM}^{4} \\
D M M\end{array}$ \\
\hline \multicolumn{5}{|c|}{$\begin{array}{c}\text { Capim-marandu } \\
\text { Marandugrass }\end{array}$} \\
\hline $\begin{array}{l}10,20 \pm 5,20 \\
16,90 \pm 8,39 \\
18,12 \pm 6,34 \\
28,90 \pm 11,22 \\
32,52 \pm 10,21 \\
50,50 \pm 16,84\end{array}$ & $\begin{array}{l}1,81 \pm 1,09 \\
2,87 \pm 0,96 \\
3,10 \pm 0,84 \\
3,39 \pm 1,25 \\
2,70 \pm 1,04 \\
5,42 \pm 1,98\end{array}$ & $\begin{array}{l}0,43 \pm 0,28 \\
0,95 \pm 0,35 \\
1,12 \pm 0,6 \\
1,39 \pm 0,76 \\
1,16 \pm 0,41 \\
2,03 \pm 0,73\end{array}$ & $\begin{array}{l}0,89 \pm 0,55 \\
1,21 \pm 0,46 \\
1,19 \pm 0,39 \\
1,26 \pm 0,61 \\
1,03 \pm 0,43 \\
2,90 \pm 1,20\end{array}$ & $\begin{array}{l}0,49 \pm 0,29 \\
0,73 \pm 0,33 \\
0,84 \pm 0,37 \\
0,75 \pm 0,41 \\
0,50 \pm 0,41 \\
0,48 \pm 0,17\end{array}$ \\
\hline \multicolumn{5}{|c|}{$\begin{array}{c}\text { Capim-tanzânia } \\
\text { Tanzaniagrass }\end{array}$} \\
\hline $\begin{array}{l}19,77 \pm 8,22 \\
28,72 \pm 9,52 \\
30,48 \pm 11,44 \\
44,80 \pm 18,01 \\
45,54 \pm 14,78 \\
83,41 \pm 15,89\end{array}$ & $\begin{array}{l}5,96 \pm 3,10 \\
6,32 \pm 3,98 \\
4,77 \pm 2,92 \\
6,00 \pm 3,10 \\
5,12 \pm 3,86 \\
5,54 \pm 1,26\end{array}$ & $\begin{array}{l}1,88 \pm 0,89 \\
2,29 \pm 1,64 \\
1,48 \pm 0,90 \\
2,87 \pm 1,95 \\
2,11 \pm 1,38 \\
3,02 \pm 0,68\end{array}$ & $\begin{array}{l}1,16 \pm 0,70 \\
2,06 \pm 1,48 \\
1,52 \pm 0,85 \\
1,85 \pm 0,97 \\
1,55 \pm 1,01 \\
1,81 \pm 0,41\end{array}$ & $\begin{array}{l}2,93 \pm 1,91 \\
1,96 \pm 1,51 \\
1,78 \pm 1,42 \\
1,31 \pm 1,35 \\
1,46 \pm 2,20 \\
0,72 \pm 0,16\end{array}$ \\
\hline
\end{tabular}

${ }^{1} \mathrm{MF}$ (massa de forragem, t MS/ha), ${ }^{2} \mathrm{MLV}$ (massa de lâminas verdes, t MS/ha), ${ }^{3} \mathrm{MHV}$ (massa de hastes verdes, t MS/ha), ${ }^{4} \mathrm{MMM}$ (massa de material morto, t MS/ha).

${ }^{1}$ FM (forage mass, $t$ DM/ha), ${ }^{2}$ GLM (green leaf mass, $\left.t D M / h a\right),{ }^{3} G S M$ (green stem mass, $\left.t D M / h a\right),{ }^{4} D M M$ (dead mattermass, $\left.t D M / h a\right)$.

Tabela 2 - Características morfológicas (médias e desvios-padrão) do amendoim forrageiro e da pastagem consorciada durante todo o período experimental

Table 2 - Morphological characteristics (means and standard deviations) of forage peanut and mixed pasture during the experimental period

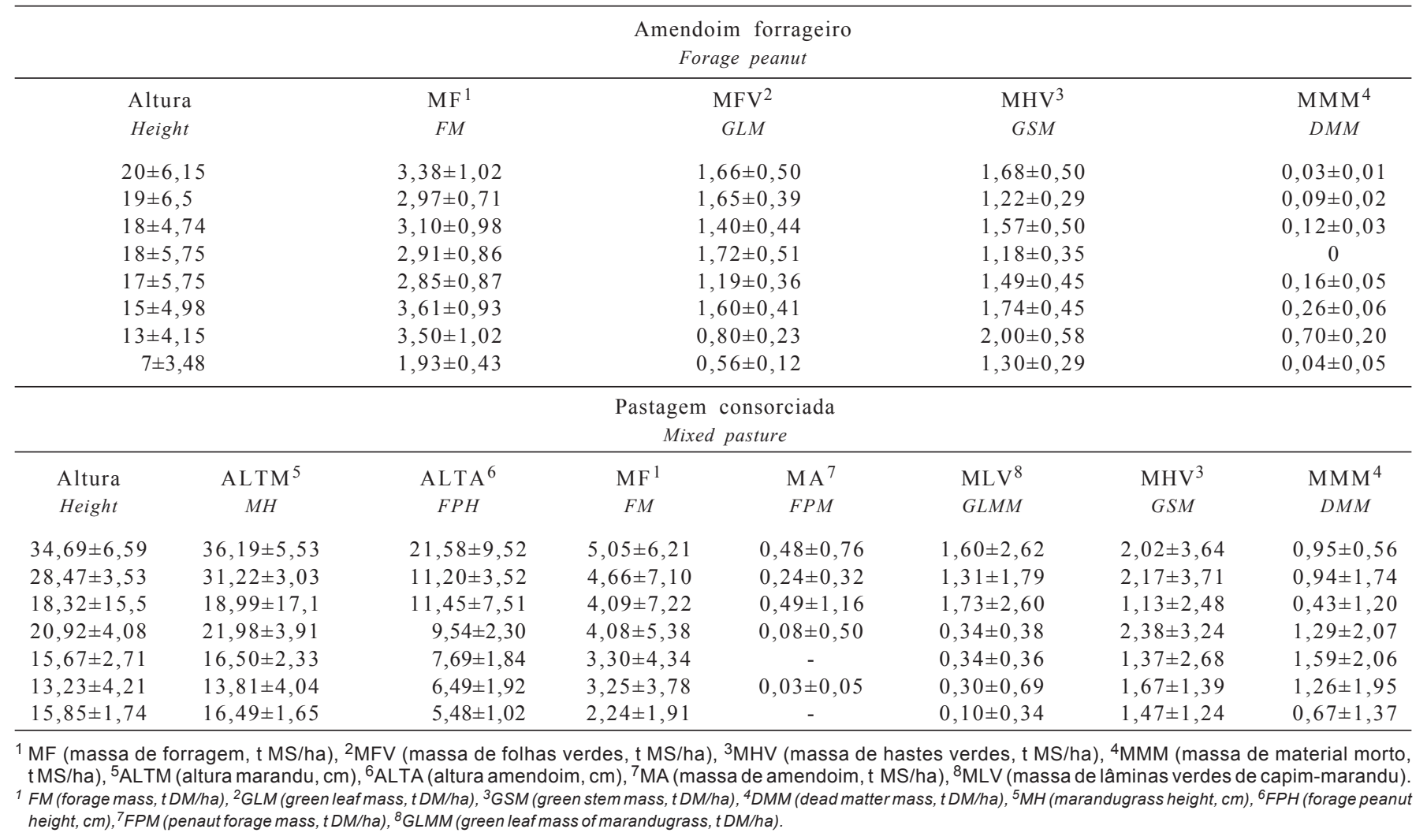


Tabela 3 - Peso vivo $(\mathrm{kg})$ e largura da arcada dentária $(\mathrm{cm})$ dos novilhos utilizados no experimento

Table 3 - Body weight $(\mathrm{kg})$ and dental arcade width $(\mathrm{cm})$ of cattle used in the trial

\begin{tabular}{lcc}
\hline $\begin{array}{l}\text { Animal } \\
\text { Animal }\end{array}$ & $\begin{array}{c}\text { Peso vivo }(\mathrm{kg}) \\
\text { Body weight }(\mathrm{kg})\end{array}$ & $\begin{array}{c}\text { Arcada dentária }(\mathrm{cm}) \\
\text { Dental arcade }(\mathrm{cm})\end{array}$ \\
\hline 1 & 327,35 & 8,00 \\
2 & 373,70 & 8,50 \\
3 & 304,15 & 8,50 \\
4 & 350,15 & 8,00 \\
5 & 329,90 & 8,00 \\
6 & 260,40 & 7,00 \\
7 & 274,25 & 7,50 \\
8 & 351,60 & 9,00 \\
9 & 305,70 & 8,00 \\
10 & 341,40 & 7,00 \\
Média & 321,86 & 7,95 \\
Mean & & \\
Desvio-padrão & 35,69 & 0,64 \\
Standard deviation & & \\
\hline
\end{tabular}

Para avaliação do comportamento ingestivo, foram utilizados dez bovinos machos, castrados, com $321,9 \mathrm{~kg}$ de peso corporal e largura média da arcada dentária de $7,95 \mathrm{~cm}$ (Tabela 3).

Apenas nas pastagens exclusivas de gramíneas, utilizaram-se todos os animais. Na pastagem consorciada, utilizaram-se oito e na de leguminosa seis animais, pertencentes ao grupo dos oito, que, por sua vez, fazia parte daqueles que pastejaram as gramíneas.

Os animais permaneceram nas parcelas experimentais apenas durante as medições - exceto para as avaliações na pastagem consorciada, na qual os animais permaneceram todo o tempo nas parcelas - e, no restante do tempo, foram mantidos em parcelas de gramíneas adjacentes.

Para as avaliações nas gramíneas, os animais foram submetidos ao pastejo em pares, passando por todas as parcelas em dias sucessivos. $\mathrm{Na}$ área de amendoim forrageiro, no entanto, os animais pastejaram juntos e, na área da pastagem consorciada, permaneceram na mesma parcela, em pares, durante todo período experimental.

O comportamento ingestivo animal foi avaliado em um curto período de pastejo (60 minutos) e a quantidade de forragem ingerida foi mensurada após jejum de 3 horas, pela técnica de dupla pesagem (Penning \& Hooper, 1985), que consiste em pesar o animal antes (peso inicial) e após o pastejo (peso final) em balança com precisão de $50 \mathrm{~g}$. Para contabilizar as perdas por fezes e urina durante as avaliações, foram colocadas bolsas coletoras nos animais. Após a pesagem inicial, os animais eram encaminhados às parcelas experimentais e observados, individualmente, por uma pessoa previamente treinada, que quantificava o tempo efetivo de pastejo, utilizando cronômetro, e o número de bocados, com o auxílio de um contador. Durante esse período, os animais não tinham acesso a água.

$\mathrm{O}$ número de bocados $(\mathrm{NB})$ por minuto foi estimado pelo quociente entre o número de bocados pelo tempo efetivo de pastejo e foi utilizado no cálculo do tempo por bocado (TB, segundos/bocado): $\mathrm{TB}=1 /\left(\mathrm{NB} \cdot \mathrm{min}^{-1}\right), \mathrm{TB}=$ $(\min x 60) / \mathrm{NB}$.

A taxa de ingestão (TI) foi obtida conforme Prache et al. (1998):

$\mathrm{TI}(\mathrm{g} / \mathrm{min})=\frac{(\text { peso final }- \text { peso inicial })+\text { perda metabólica }}{\text { tempo pastejo efetivo }(\min )}$

A ingestão por bocado (IB; g MS) foi obtida dividindo-se o acúmulo de peso pelo total de bocados no período.

O ganho de peso dos animais após o pastejo de 1 hora foi corrigido para perda de peso metabólico. Para isso, os animais foram mantidos em curral ao sol durante 1 hora, sem água e comida, sendo pesados antes e após esse período.

A variação taxa de ingestão (TI) em função da altura (A) e da massa de folhas verdes (MFV) da pastagem foi estudada utilizando-se o modelo não-linear descrito a seguir (Damasceno et al., 2000):

$$
\mathrm{Y}=\operatorname{TImax}\left(1-\mathrm{e}^{(-\mathrm{K} \times \mathrm{Z})}\right) \text {, }
$$

em que $\mathrm{Y}=$ taxa de ingestão $(\mathrm{g} \mathrm{MS} / \mathrm{min})$; TImax $=$ parâmetro estimado pelo modelo que representa a taxa de ingestão potencial máxima ( $\mathrm{g} \mathrm{MS} / \mathrm{min}) ; \mathrm{k}=$ parâmetro que representa o incremento na ingestão, em relação à TImax, para cada unidade de aumento na altura da pastagem $(\mathrm{cm})$ ou na massa de folhas, em que $Z$ = altura da pastagem (A) em $\mathrm{cm}$; ou massa de folhas (MFV), em t MS/ha.

Assumiu-se que, à medida que a altura da pastagem ou a massa de folhas aumentam, a ingestão de MS é incrementada até atingir a taxa de ingestão potencial (TImax), tendendo à assíntota. Para cada animal, dentro de cada tipo de pastagem, foi ajustada uma curva, cujos parâmetros foram tratados como variáveis biológicas.

$\mathrm{O}$ efeito das pastagens nos parâmetros TImax e $k$ foi estudado mediante análise de variância, conforme o modelo estatístico a seguir:

$$
\mathrm{Y}_{\mathrm{ij}}=\mu \backslash \mathrm{Pi} \backslash \mathrm{A}_{\mathrm{ij}} \backslash \mathrm{e}_{\mathrm{ij}},
$$

em que $\mathrm{Y}_{\mathrm{ij}}=$ valor observado da variável estudada no indivíduo $\mathrm{j}$ na pastagem $\mathrm{i} ; \mu=$ constante geral; $\mathrm{P}_{\mathrm{i}}=$ efeito da pastagem estudada $(i=1,2,3,4) ; A_{j}=$ efeito do animal $\mathrm{j}$; $\mathrm{e}_{\mathrm{ij}}=$ erro aleatório associado a cada observação $\mathrm{Y}_{\mathrm{ij}}$.

As médias foram comparadas pelo teste Duncan $(\mathrm{P}<0,05)$ por terem sido utilizados diferentes números de animais para cada pastagem.

Dentro de cada espécie, o comportamento da taxa de ingestão em função da ingestão por bocado (IB) e do tempo por bocado (TB) foi estudado mediante análise de 
regressão polinomial e análise de correlação de Pearson, segundo Snedecor \& Cochran (1989). Para o estudo do tempo por bocado (TB, segundos) em função da ingestão por bocado (IB, g MS), ajustou-se um modelo linear por indivíduo, conforme Prache \& Peyraud (1997):

$$
\mathrm{Y}=\mathrm{a}+\mathrm{b} \text { IB, }
$$

em que $\mathrm{Y}=$ tempo por bocado (segundos); $\mathrm{a}=$ tempo necessário para apreensão da forragem (segundos), independentemente da massa por bocado; $b=$ tempo necessário para mastigação, processamento e seleção da forragem ingerida (segundos/g MS.bocado ${ }^{-1}$ ); IB = ingestão por bocado (g MS).

O efeito da espécie forrageira sobre os coeficientes $a$ e $b$ foi estudado da mesma forma que os parâmetros dos modelos não-lineares ajustados para a altura e a massa de folhas. Todas as análises dos dados foram realizadas utilizando-se o programa estatístico SAEG - UFV (1993).

\section{Resultados e Discussão}

A taxa de ingestão (TI) nas diferentes pastagens variou conforme a altura da pastagem (A) (Figura 1a,b). A elevação na altura da pastagem proporcionou incrementos na TI das pastagens avaliadas, provavelmente em razão dos efeitos positivos na profundidade de pastejo (Hodgson, 1990; Flores et al., 1993).

A manutenção da altura da pastagem em $10 \mathrm{~cm}$ para o capim-marandu e $20 \mathrm{~cm}$ para o tanzânia (baixa) pode ser desestimulante para o consumo animal, pois redução severa na altura da pastagem promove decréscimo significativo na taxa de ingestão pelos animais (McGilloway et al., 1999; Orr et al., 2004).

A taxa de ingestão máxima (TImax) não variou entre as espécies ( $\mathrm{P}>0,01)$ (Tabela 4). A TImax é um parâmetro que indica o potencial de ingestão instantânea de uma espécie ou pastagem. É desejável que este valor seja o mais elevado possível, pois define, para cada espécie forrageira, o grau de facilidade com que o animal colhe as plantas e tem impacto direto sobre o consumo a longo prazo (consumo voluntário em 24 horas, por exemplo).

Observou-se superioridade da leguminosa $(\mathrm{P}<0,01)$ para os valores de $\mathrm{k}$ (taxa de ingestão por $\mathrm{cm}$ de altura da pastagem), com uma constante de 0,09 , que indica que a leguminosa em cultivo exclusivo é mais sensível às variações na altura (Tabela 4), porém, quando consorciada com o capim-marandu, apresentou-se como as demais pastagens $(\mathrm{P}>0,05)$. Ou seja, para a mesma altura, a TI foi maior na pastagem exclusiva de amendoim forrageiro que na consorciada; ou ainda, a TImax na pastagem consorciada
Tabela 4 - Taxa de ingestão potencial (TImax) e constante $(K)$ em função da altura da pastagem (A)

Table 4 - Potential ingestion rate (IR) and constant $k$ according to sward height $(H)$

\begin{tabular}{lcc}
\hline $\begin{array}{l}\text { Pastagem } \\
\text { Pasture }\end{array}$ & $\begin{array}{c}\text { TImax } \\
\text { RImax }\end{array}$ & $\mathrm{k}$ \\
\hline $\begin{array}{l}\text { Amendoim forrageiro } \\
\begin{array}{l}\text { Forage peanut } \\
\text { Capim-marandu }\end{array}\end{array}$ & $51,65 \mathrm{~A}$ & $0,0926 \mathrm{~A}$ \\
$\begin{array}{l}\text { Marandugrass } \\
\text { Consorciação }\end{array}$ & $65,68 \mathrm{~A}$ & $0,0490 \mathrm{~B}$ \\
$\begin{array}{l}\text { Mixed sward } \\
\text { Tanzânia } \\
\text { Tanzaniagrass } \\
\begin{array}{l}\text { Média } \\
\text { Mean }\end{array}\end{array}$ & $73,68 \mathrm{~A}$ & $0,0312 \mathrm{~B}$ \\
\end{tabular}

Médias na coluna seguidas de letras distintas diferem $(P<0,05)$ pelo teste Duncan.

Means within a column followed by different letters differ $(P<0.05)$ by Duncan test.

a)

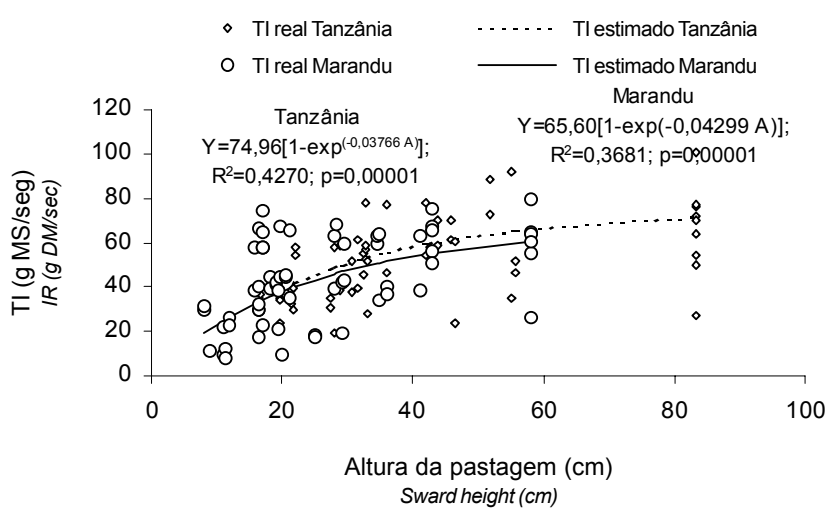

b)

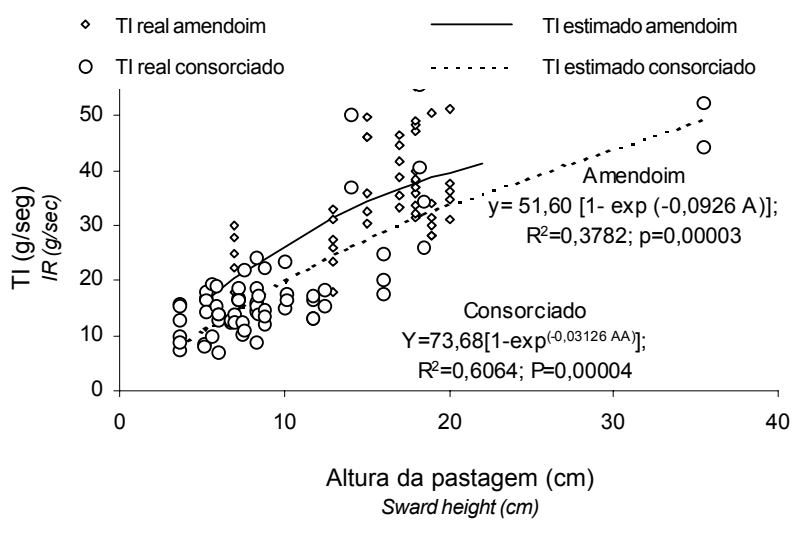

Figura 1 - Taxa de ingestão (TI, g MS/min) em função da altura da pastagem (A): a) capins tanzânia e marandu; b) amendoim forrageiro e pastagem consorciada.

Figure 1 - Ingestion rate (IR, g DM/min) according to sward height (A): a) tanzaniagrass and marandugrass, b) forage peanut and mixed pasture. 
seria atingida em uma altura superior, possivelmente em virtude da maior dificuldade do animal em selecionar os itens preferidos em um ambiente mais heterogêneo, como se caracterizam os sistemas de consórcio de diferentes espécies.

É coerente que a TI em pastagens de porte alto, como as dos gêneros Panicum e Brachiaria, seja menos sensível a variações na altura, pois o impacto do bocado é proporcionalmente maior em pastagens de porte baixo, como a de amendoim forrageiro, atingindo mesma TI potencial em menor altura, se comparadas a pastagens com espécies de porte alto. Contudo, sabe-se que em plantas cespitosas o consumo animal é facilitado pela altura das plantas.

Um dos pontos favoráveis ao consumo na pastagem de amendoim forrageiro foi a grande proporção de folhas (Tabela 2) (Prache et al., 1998; Euclides et al., 1999) e os baixos teores de FDN no dossel (Van Soest, 1994).

A taxa de ingestão na pastagem consorciada não teve relação com a altura média do capim-marandu (ALTM) ou com a altura total (ALTT), apresentando melhor ajuste em função da altura do amendoim forrageiro (ALTA) (Figura 1a), demonstrando que a distribuição espacial desta espécie no relvado foi fator determinante da TI, provavelmente pela preferência dos animais pela leguminosa. Quando a pastagem estava mais alta, a acessibilidade dos animais ao pastejo era facilitada, ocorrendo incremento na TI.

As TI avaliadas nas diferentes pastagens apresentaram ajuste em função da altura. Ressalta-se, contudo, que alguns animais foram retirados do modelo por não apresentar respostas significativas, o que demonstra a importância de se considerar a variabilidade entre indivíduos. Diferenças fisiológicas, morfológicas e de experiência prévia de pastejo entre os animais influenciam na seletividade e no consumo

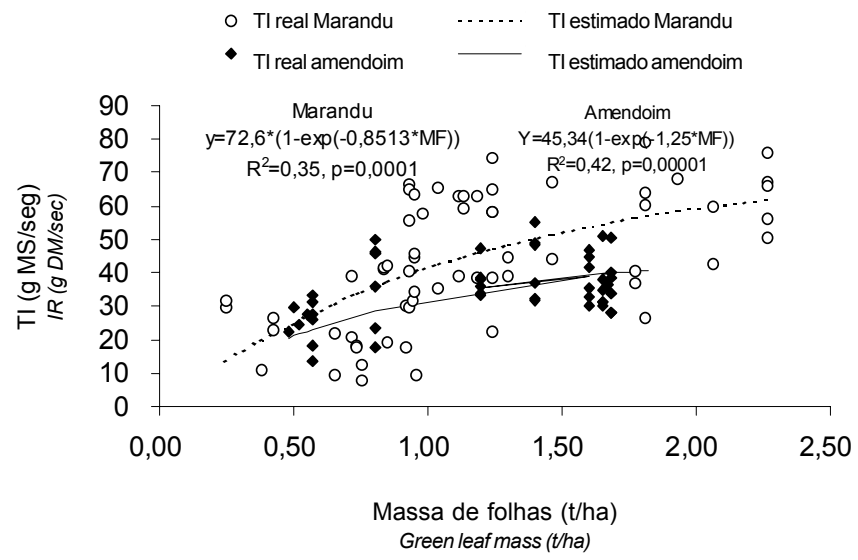

Figura 2 - Taxa de ingestão (TI) pelos animais em função da massa de folhas verdes (MFV) em pastagens de amendoim forrageiro e capim-marandu.

Figure 2 - Ingestion rate (IR) according to green leaf mass (GLM) in pastures of forage peanut and marandugrass.
(Newman, 1995). A experiência prévia dos animais em sistemas de pastejo, no entanto, era desconhecida.

Neste trabalho, houve efeito positivo da massa de folhas no relvado (MFV) sobre a TI no amendoim forrageiro e no capim-marandu (Figura 2), mas não houve ajuste em relação à MFV no capim-tanzânia e na pastagem consorciada.

O capim-marandu apresentou maior TImax em função da MFV em relação à leguminosa (Tabela 5). Apesar de a TImax ter sido superior para a gramínea, o valor de $\mathrm{K}$ foi superior para a leguminosa, comprovando que a TI no amendoim forrageiro é mais sensível às variações na massa de folhas no relvado que no capim-marandu. Ou seja, a superioridade da TI na gramínea pode ser atribuída à arquitetura da planta, que é mais favorável ao aparelho bucal do animal e ao hábito de pastejo bovino, proporcionando maior profundidade e volume de bocado, o que provavelmente acarretaria maior TI (Hodgson, 1990; Gordon \& Illius, 1996; Carvalho, 2001). Entretanto, o valor de k superior na leguminosa demonstra que a massa de folhas na arquitetura do amendoim incrementa o consumo animal.

Na pastagem de amendoim forrageiro, a TI dos animais variou de 13,4 a 55,2 g MS/min e a MFV de 0,55 a 1,7 t MS/ha (Tabela 2). Na pastagem de capim-marandu, a TI variou de 7,96 a 79,29 g MS/min, com os menores valores para as pastagens com menor altura $(10 \mathrm{~cm})$ e menor massa de folhas $(0,43 \mathrm{t}$ ) (Tabela 1). Esses resultados demonstram o prejuízo na ingestão de MS por esses animais. Em trabalho realizado com bovinos em pastagem de Paspalum dilatatum, os valores observados para TI foram de 2,18 a 24,55 g MS/min, em função de diferentes estruturas (Ungar et al., 1991).

Comparando as variáveis altura e massa de folhas, utilizadas para correlacionar com a TI, verificou-se que seus correspondentes coeficientes de determinação foram semelhantes, ambos relativamente baixos (inferiores a 0,40 , Figuras 1 e 2), o que implica interferência de outras variáveis atuando no comportamento ingestivo animal, como, por exemplo, de algumas propriedades estruturais

Tabela 5 - Taxa de ingestão potencial (TImax) e constante $K$ em função da massa de folhas verdes (MFV)

Table 5 - Potencial ingestion rate (IR) and constant $K$ according to green leaf mass (GLM)

\begin{tabular}{lcc}
\hline $\begin{array}{l}\text { Pastagem } \\
\text { Pasture }\end{array}$ & $\begin{array}{c}\text { TImax } \\
\text { TImax }\end{array}$ & $\begin{array}{c}\mathrm{k} \\
k\end{array}$ \\
\hline $\begin{array}{l}\text { Amendoim forrageiro } \\
\text { Forage peanut }\end{array}$ & $45,34 \pm 12,65 \mathrm{~B}$ & $1,25 \pm 0,58 \mathrm{~A}$ \\
$\begin{array}{l}\text { Capim-marandu } \\
\text { Marandugrass }\end{array}$ & $72,60 \pm 14,76 \mathrm{~A}$ & $0,85 \pm 0,27 \mathrm{~B}$ \\
& &
\end{tabular}

Médias na coluna seguidas de letras distintas diferem $(P<0,05)$ pelo teste Duncan.

Means, within a column, folowed by different letters differ $(P<0.05)$ by Duncan test. 
referentes às folhas e hastes e ao conteúdo de fibra (Wright \& Illius, 1995).

A taxa de ingestão por bocado (IB, g MS) provocou efeito linear positivo sobre a TI nas diferentes pastagens estudadas (Figura 3c,d), demonstrando que, quanto maior a massa do bocado, maior a TI do animal. A IB variou de 0,43 a 2,51 g MS/bocado na pastagem de amendoim forrageiro; de 0,32 a 3,77 g MS/bocado na de capim-marandu; de 0,32 a 2,19 g MS/bocado na pastagem consorciada; e de 0,81 a 3,84 g MS/bocado na de capim-tanzânia. Na pastagem de capim-marandu mantida a $10 \mathrm{~cm}$, a IB foi de $0,32 \mathrm{~g}$ MS e, naquela mantida a $50 \mathrm{~cm}$, de $3,77 \mathrm{~g}$ MS, confirmando os achados de Sarmento (2003), que observou massas de bocado entre 0,5 a 1,7 g MS/bocado (em bovinos) nas pastagens de 10 e $40 \mathrm{~cm}$ de altura, respectivamente.

As regressões entre a TI em função do tempo por bocado (TB) nas diferentes pastagens são representadas

a)

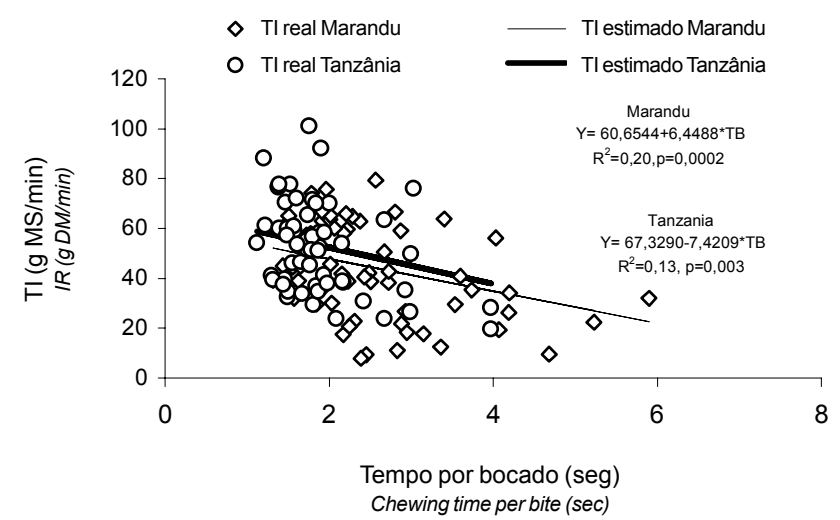

c)

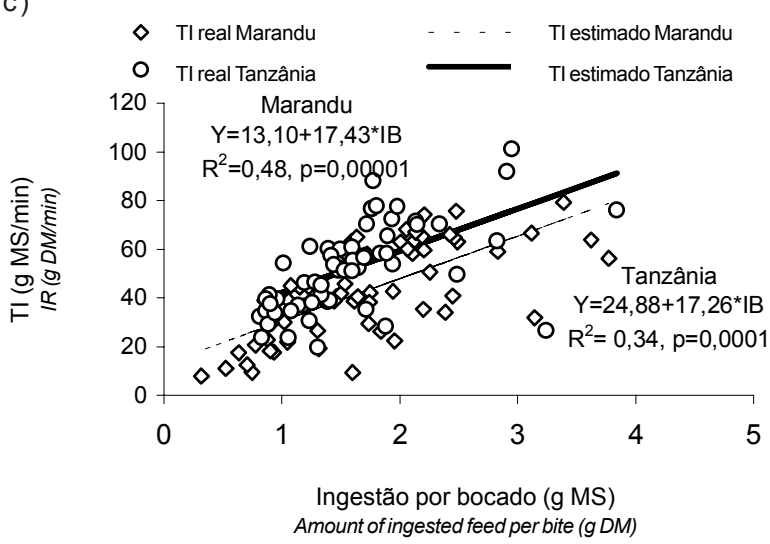

na Figura $3(a, b)$. Houve redução linear da TI em função do TB, ou seja, o aumento no tempo despendido pelos animais para efetuar o bocado promoveu reduções na TI, influenciando a estrutura da pastagem, visto que pastagens com estruturas com maior facilidade de apreensão e mastigação resultam em menor tempo por bocado e, conseqüentemente, em maiores TI. Ressalta-se, no entanto, que, pelos baixos valores de $\mathrm{R}^{2}$, existem também outras variáveis interferindo no comportamento ingestivo animal.

O tempo por bocado (segundos/bocado) variou de 1,23 a 3,62 para a pastagem de amendoim forrageiro, de 1,32 a 5,90 para a de capim-marandu, de 1,12 a 3,97 para a de capimtanzânia e de 1,32 a 9,03 para a pastagem consorciada (valores mínimo e máximo, respectivamente). O maior tempo gasto para efetuar o bocado pode ser decorrente da maior massa ingerida (ingestão por bocado) ou das características estruturais (relação folha:haste) e químicas da planta, como

b)

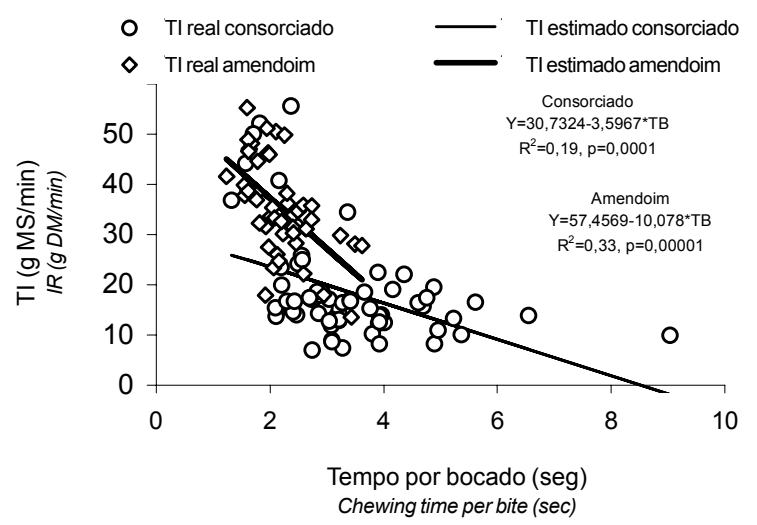

d)

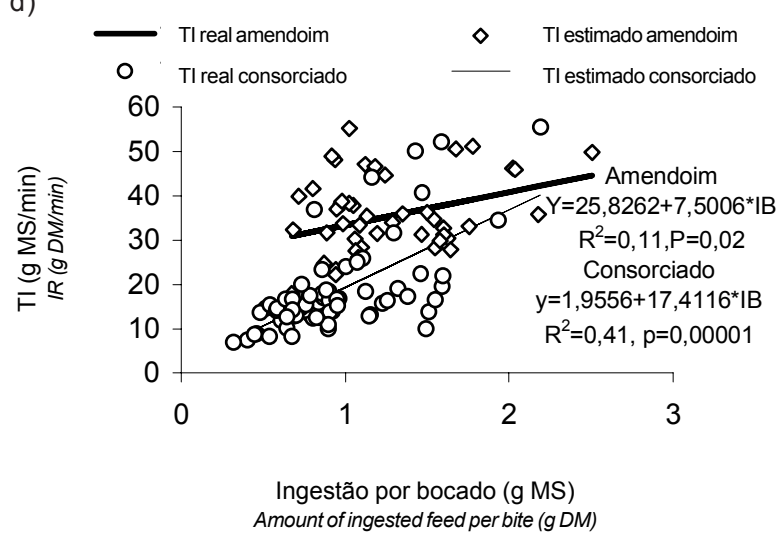

Figura 3 - Taxa de ingestão (TI, g MS/min), em função do tempo por bocado (segundos) (a, b) e da ingestão por bocado (IB, g MS) em pastagens de capim-marandu, capim-tanzânia $(a, b)$ e amendoim forrageiro e em pastagem consorciada (c, d).

Figure 3 - Ingestion rate (IR, g DM/min) according to chewing time (seconds) $(a, b)$ and amount of ingested feed per bite (IB, $g$ DM) of marandugrass and tanzaniagrass $(a, b)$ and forage peanut and mixed pasture $(c, d)$. 
o teor de FDN, que resulta em maior tempo de mastigação (Orr et al., 2004), o que explica o menor tempo gasto nos bocados na pastagem exclusiva da leguminosa, a qual apresentou os menores teores de FDN.

As regressões de TI em função da ingestão por bocado (IB) e do tempo por bocado (TB) indicam como o animal modula seu comportamento para maximizar a ingestão, ou seja, buscando sempre aumentar a taxa de ingestão. Entretanto, o perfil vertical de cada pastagem avaliada apresenta variações em sua composição em folhas, hastes e material morto de acordo com a altura (estrutura). Isso indica que a pastagem pode se apresentar ao animal com características favoráveis ou desfavoráveis à potencialização do consumo. Pelo comportamento seletivo do animal, pressupõe-se que ele utilize estratégias para minimizar os efeitos negativos na variação estrutural da planta sobre a TI (Prache et al., 1998).

Uma das estratégias utilizadas pelo animal quando ocorre redução na ingestão por bocado, decorrente das condições desfavoráveis da pastagem (redução na altura e proporção de folhas e aumento da proporção de hastes e de material morto), é aumentar a taxa de bocados (bocados por minuto) ou, de forma análoga, mudanças positivas na estrutura da pastagem podem resultar em aumento na ingestão por bocado e na diminuição da taxa de bocados. Espera-se que maiores valores de ingestão por bocado resultem em maior tempo por bocado (Hodgson, 1990).

As correlações entre a TI e as variáveis do bocado auxiliam no entendimento das estratégias utilizadas pelo animal na formação do bocado (Tabela 6), visto que o animal modula sua TI de acordo com a pastagem. Na pastagem de amendoim forrageiro, por exemplo, o TB foi a variável mais correlacionada com TI, enquanto, nas gramíneas e na pastagem consorciada, a IB foi de maior relevância.

Parece que, na pastagem de amendoim forrageiro, o animal procurou maximizar sua ingestão por meio do aumento na taxa de bocados, talvez em razão dos menores valores alcançados na IB (0,43 a 2,51 g MS/bocado). O tempo por bocado depende da facilidade de apreensão e mastigação, influenciada pelas características estruturais da pastagem e pelo teor de fibra da planta (Roguet et al., 1998). De fato, as características do amendoim forrageiro são favoráveis à apreensão e ao rápido processamento da forragem (Tabela 1). Entretanto, deve-se ressaltar que a estratégia de aumentar a taxa de bocados para maximizar a TI implica maior gasto de energia por unidade de MS consumida. Provavelmente, acréscimos na ingestão por bocado sejam mais interessantes para o animal, em razão do menor custo energético por unidade de MS ingerida.
A IB apresentou correlação positiva com a TI em todas as pastagens avaliadas e pode ser considerada a variável mais importante para as pastagens de capim-marandu, capim-tanzânia e consorciada, conforme constatado para outras espécies (Ungar et al., 1991).

O tempo por bocado (TB), expresso em segundos, apresentou correlação negativa com a TI em todas as pastagens, indicando que, quanto maior o tempo de manipulação do alimento, menor a TI.

A IB teve correlação positiva com o TB, mostrando que, quanto maior a massa de forragem ingerida pelo animal, maior o tempo para manipular o alimento e menor a taxa de bocados (número de bocados por minuto). Entretanto, estudos têm comprovado que, na maioria das vezes, o aumento no número de bocados geralmente não compensa a redução no peso do bocado (Ungar et al.,1991) para manter elevados os valores de TI.

Não houve diferença significativa no tempo despendido para a apreensão de cada bocado (a) entre as diferentes pastagens (Tabela 7). O tempo de manipulação/g MS ingerido/bocado foi influenciado pela pastagem $(\mathrm{P}<0,05)$,

Tabela 6 - Correlações de Pearson entre a taxa de ingestão (TI) e as características do bocado

Table 6 - Pearson correlations between ingestion rate (IR) and chewing activity

\begin{tabular}{|c|c|c|c|}
\hline \multirow[t]{2}{*}{$\begin{array}{l}\text { Pastagem } \\
\text { Sward }\end{array}$} & \multicolumn{3}{|c|}{$\begin{array}{c}\text { Amendoim forrageiro } \\
\text { Forage peanut }\end{array}$} \\
\hline & T I & IB & TB \\
\hline & $I R$ & $I F B$ & CTB \\
\hline T I & & $0,33 * *$ & $-0,57 * *$ \\
\hline IB & $0,33 * *$ & & $0,34 * *$ \\
\hline \multirow{2}{*}{$\mathrm{TB}$} & $-0,57 * *$ & $0,34 * *$ & \\
\hline & & $\begin{array}{l}\mathrm{m} \text {-mara } \\
\text { randugra }\end{array}$ & \\
\hline T I & & $0,69 * *$ & $-0,45 * *$ \\
\hline IB & $0,69 * *$ & & 0,18 \\
\hline TB & $-0,45$ & 0,18 & \\
\hline
\end{tabular}

Consorciação

Mixed

\begin{tabular}{lccc} 
T I & $0,93 * *$ & $-0,44$ \\
IB & $0,93 * *$ & $0,48 * *$ \\
TB & $-0,44$ & $0,48 * *$ & \\
\hline \multicolumn{3}{c}{ Capim-tanzânia } \\
& Tanzaniagrass \\
T I & $0,59 * *$ & $-0,37 * *$ \\
IB & $0,59 * *$ & & $0,46 * *$ \\
TB & $-0,37 * *$ & 0,46 & \\
\hline
\end{tabular}

${ }^{*}$ significativo a $5 \%,{ }^{* *}$ significativo a $1 \%$.

*significant at $5 \%,{ }^{* *}$ significant at $1 \%$.

$\mathrm{TI}$ - taxa de ingestão (g MS/minuto), IB - Ingestão por bocado (g MS), TB - tempo por bocado (segundos).

IR-Ingestion rate (gDM/min), IFB-amount of ingested feed per bite ( $g$ DM), CTB-chewing time perbite (seconds). 
sendo superior na pastagem de capim-tanzânia e na consorciada.

Em média, foram despendidos 3,09 segundos/g MS/ bocado para a manipulação das pastagens de capim-tanzânia e consorciada, enquanto, para a de amendoim forrageiro e a de capim-marandu, o tempo médio foi de 0,7451 segundo/ g MS/bocado.

O tempo de manipulação do bocado (b) é uma característica dependente das características estruturais e qualitativas da planta (Prache \& Peyraud, 1997). Quanto maior o valor de $b$, maior a facilidade de processamento do material ingerido. As leguminosas e gramíneas temperadas são mais facilmente quebradas durante a mastigação que as gramíneas tropicais (Minson \& Wilson, 1980).

É importante ressaltar que o capim-marandu cultivado de forma exclusiva apresentou condições mais favoráveis à apreensão e mastigação que na pastagem consorciada, proporcionando maior oferta de massa verde, maior massa de folhas e menor quantidade de material morto (Tabelas 1 e 2).

Para o capim-tanzânia, este modelo se ajustou para todos os animais. Entretanto, para as pastagens de amendoim forrageiro, capim-marandu e para a consorciação, houve ajuste apenas para três animais, o que evidencia a importância da variação entre animais, principalmente quanto ao grau de seletividade individual. Este resultado indica que experimentos desta natureza devem contar com grupos de animais homogêneos, criados no mesmo sistema de produção, com as mesmas experiências de manejo alimentar e as mesmas condições ambientais.

Tabela 7 - Médias dos coeficientes a e b (TB = a +bIB) e desviospadrão nas diferentes pastagens

Table 7 - Means of $a$ and $b$ coefficients $(T B=a+b / B)$ from pastures of different forage species

\begin{tabular}{lcc}
\hline $\begin{array}{l}\text { Pastagem } \\
\text { Pasture }\end{array}$ & $\mathrm{a}$ & $\mathrm{b}$ \\
\hline $\begin{array}{l}\text { Capim-tanzânia } \\
\text { Tanzaniagrass } \\
\text { Capim-marandu }\end{array}$ & $0,4301 \pm 0,2990 \mathrm{~A}$ & $3,1615 \pm 0,8485 \mathrm{~A}$ \\
$\begin{array}{l}\text { Marandugrass } \\
\text { Amendoim forrageiro }\end{array}$ & $0,9670 \pm 0,8177 \mathrm{~A}$ & $0,8056 \pm 0,4759 \mathrm{~B}$ \\
$\begin{array}{l}\text { Forage peanut } \\
\text { Pastagem consorciada }\end{array}$ & $0,8673 \pm 1,3010 \mathrm{~A}$ & $2,8362 \pm 1,7976 \mathrm{~A}$ \\
$\begin{array}{l}\text { Mixed pasture } \\
\text { Coeficiente de variação }\end{array}$ & 92,52 & 36,48 \\
$\begin{array}{l}\text { Coeficient of variation } \\
\text { Média }\end{array}$ & 0,7271 & 2,3471 \\
Mean & & $0,6845 \pm 0,0738 \mathrm{~B}$ \\
\hline
\end{tabular}

Médias na coluna seguidas de letras distintas diferem $(P<0,05)$ pelo teste Duncan.

Means within a column followed by different letters differ $(P<0.05)$ by Duncan test.

\section{Conclusões}

A taxa de ingestão instantânea pelos animais nas pastagens tropicais exclusivas e na consorciação é intensificada pela altura da pastagem.

As características do bocado animal são influenciadas pelas diferentes estruturas da pastagem: a estrutura da leguminosa exclusiva proporciona aumento na taxa de bocados e diminuição no tempo de manipulação do bocado, enquanto as gramíneas tropicais exclusivas e a consorciação favorecem o aumento na ingestão por bocado.

Os baixos coeficientes de determinação dos modelos apresentados indicam a existência de outras variáveis relevantes afetando o comportamento ingestivo animal, além da altura do relvado e da massa de folhas verdes.

\section{Literatura Citada}

CARVALHO, P.C.F.; RIBEIRO FILHO, H.M.N.; POLI, C.H.E. et al. Importância da estrutura da pastagem na ingestão e seleção de dietas pelo animal em pastejo. In: MATTOS, W.R.S. (Ed). A produção animal na visão dos brasileiros. Piracicaba: Fundação de Estudos Agrários Luiz de Queiroz, 2001, p.853871 .

COMBELLAS, J.; HODGSON, J. Herbage intake and milk production by grazing dairy cows. 1 . The effects of variation in herbage mass and daily herbage allowance on short term trial. Grass and Forrage Science, v.34, p.209-214, 1979.

CORRÊA, A.R. Forrageiras: aptidão climática do Estado do Paraná. In: MONTEIRO, A.L.; MORAES, A.; CORRÊA, E.A.S. et al. (Eds.) Forragicultura no Paraná. 1.ed. Londrina: Comissão Paranaense de Avaliação de Forrageiras, 1996. p.15-22.

DAMASCENO, J.C.; SANTOS, G.T.; CECATO, U. et al. Consumo voluntário, digestibilidade e balanço de nitrogênio em ovinos recebendo palha de arroz amonizada em diferentes níveis de oferta. Revista Brasileira de Zootecnia, v.29, n.4, p.1167$1173,2000$.

EMPRESA BRASILEIRA DE PESQUISA AGROPECUÁRIA EMBRAPA. Centro Nacional de Pesquisa de Solos. Sistema brasileiro de classificação de solos. Rio de Janeiro, 1999. $412 \mathrm{p}$.

EUCLIDES, V.P.B.; THIAGO, L.R.L.S.; MACEDO, M.C.M. et al. Consumo de forragem de três cultivares de Panicum maximum sob pastejo. Revista Brasileira de Zootecnia, v.28, n.6, p.1177-1185, 1999.

FLORES, E.R.; LACA, E.A.; GRIGGS, T.C. et al. Sward height and vertical morphological differentiation determine cattle bite dimensions. Agronomy Journal, v.85, n.3, p.527-532, 1993.

GORDON, I.J.; ILLIUS, A.W.; MILNE, J.D. Sources of variation in foraging efficiency of grazing ruminants. Functional Ecology, v.10, p.219-226, 1996.

HODGSON, J. Variations in the surface characteristics of the sward and the short-term rate of herbage intake by calves and lambs. Grass and Forage Science, v.36, p.49-57, 1981.

HODGSON, J. Grazing management: science into practice. New York: John Willey, 1990. 203p.

MCGILLOWAY, D.A.; CHUSHNAHAN, A.; LAIDLAW, A.S. et al. The relationship between level of sward height reduction in a rotationally grazed sward and short-term intake rates of dairy cows. Grass and Forage Science, v.54, p.116-126, 1999.

MINSON, D.J.; WILSON, J.R. Comparative digestibility of tropical and temperate forage, a contrast between grasses and legumes. 
Journal of the Australian Institute of Agricultural Science, v.46, p.247-249, 1980.

NEWMAN, J.A.; THOMPSON, W.A.; PENNING, P.D. Leastsquares estimation of diet composition from $n$-alkanes in herbage and faces using matrix mathematics. Australian Journal Agricultural Research, v.46, p.793-805, 1995.

ORR, R.J.; RUTTER, S.M.; YARROW, N.M. et al. Changes in ingestive behavior of yarling dairy heifers due to changes in sward state during grazing down down of rotationnally stocked ryegrass or white clover pastures. Applied Animal Behavior Science, v. 87, p.205-222, 2004.

PENNING, P.D.; HOOPER, G.E. Evaluation of the use of shortterm weight changes in sheep to estimate herbage intake. Grass and Forrage Science, v.40, p.79-84, 1985.

POPP, J.D.; McCAUGHEY, W.P.; COHEN, R.D.H. Effect of grazing system, stocking rate and season of use on herbage intake and grazing behavior of stocker cattle grazing alfafagrass pastures. Canadian Journal of Animal Science, v.77, p.677-682, 1997.

PRACHE, S.; PEYRAUD, J.L. Préhensibilité de 1'herbe pâturée chez lez bovins et les ovins. INRA Production Animales, v.10, p.377-390, 1997.

PRACHE, S.; GORDONS, I.J.; ROOK, A.J. Foraging behavior and diet selection in domestic herbivores. Annales Zootechnie, v.47, p.1-11, 1998.

ROGUET, C.; DUMONT, B.; PRACHE, S. Selection and use of feeding sites and feeding stations by herbivores: a review. Annes de Zootechnie, v.47, p.225-244, 1998.
SARMENTO, L.S. O comportamento ingestivo de bovinos em pastos de capim Marandu submetidos a regimes de lotação contínua. Piracicaba. Escola Superior de Agricultura "Luiz de Queiroz", 2003. 76p. Dissertação (Mestrado em Agronomia) Escola Superior de Agricultura "Luiz de Queiroz", 2003.

SNEDECOR, G.; COCHRAM, W.G. Statistical methods. 8.ed. Ames: The Iwoa State University Press, 1989. 503p.

UNGAR, E.D.; GENIZI, A.; DEMMENT, M.W. Bite dimensions and herbage intake by cattle grazing short hand-constructes swards. Agronomy Journal, v.83, p.973-978, 1991.

UNGAR, E.D. Ingestive behavior. In: HODGSON, J.; ILLIUS, A.W (Eds.) The ecology and management of grazing systems. Wallingford: CAB international, 1996. p.185-218.

UNIVERSIDADE FEDERAL DE VIÇOSA - UFV. SAEG - Sistema de análises estatísticas e genéticas. Versão 5.0, Viçosa, MG: 1993.

Van SOEST, P.J. Nutritional ecology of the ruminant. 2.ed. Ithaca: Cornell University Press, 1994. 476p.

WRIGHT, W.; ILLIUS, A.W. A comparative study of the fracture properties of 5 grasses. Functional Ecology, v.9, p.269-278, 1995.

Recebido: 10/01/05 Aprovado: 24/03/06 